\title{
Nota de Opinión: El alto costo y las verdades ocultas del exceso de tecnología dedicada al rastreo de personas asintomáticas
}

\author{
High cost and hidden truths of the excess of technology dedicated to screening of asymptomatic persons
}

Carlos García*

En el año 2011 se publicaron los resultados del Ensayo Nacional de Rastreo de Cáncer de Pulmón (National Lung Screening Trial-NLST) que comparó, en una población de 53.000 grandes fumadores y ex-fumadores, la efectividad de la tomografía computada de baja dosis (TCBD) versus la radiografía de tórax convencional'.

El estudio, como herramienta de prevención de muertes por cáncer de pulmón, concluye que el rastreo con TCBD reduce la mortalidad por cáncer de pulmón en un $20 \%$. En efecto, la población (fumadores de alto riesgo), el tamaño de la muestra (casi 54.000 individuos), el diseño (prospectivo, aleatorizado y multicéntrico) y su análisis no arrojan dudas sobre sus conclusiones.

Semejante "impacto" poblacional, es decir una reducción de 20 por ciento de la mortalidad por una patología tan dañina como es el cáncer de pulmón, hizo que sus ecos no demoraran lo que canta un gallo en oírse $e^{2,3,4,5,6}$.

Como suele ocurrir, no es infrecuente encontrar comentarios con escaso rigor científico en donde no se explicitan claramente los conflictos de intereses existentes (donde en general quien apoya una técnica novedosa suele beneficiarse económicamente directa o indirectamente con su utilización). Los diarios, las radios y la televisión gritan a viva voz la nueva panacea. Si tenemos la doble desgracia de que algún actor o actriz de renombre tenga justo cáncer de pulmón en ese momento, podemos cantar cartón lleno.

El médico-periodista radial colaborador del periodista estrella conductor de esa especie de living en que se convirtieron algunos programas radiales, de voz más clara que el agua mineral, llamará al actor, llamará a un médico-experto y los pondrá en contacto. El actor llorará y agradecerá (en el caso, claro está, en que suponga que esta nueva tecnología lo ha salvado), el médico-experto difundirá el nuevo chiche y el médicoperiodista vociferará que el actor se curará, que el médicoexperto es cada vez más médico y más experto, que el nuevo chiche está listo para ser usado y que el cáncer de pulmón será cosa del pasado si la ciencia sigue así.

Y atrás, bien atrás, venimos los amargos, los aguafiestas, los que, como yo, quieren explicar un poco mejor estos "avances" (siguen las comillas) y que ni por asomo podemos mostrar el hocico por las radios, los diarios o la televisión.

Vayamos al análisis de nuestro estudio: ¿Qué significa que la TCBD redujo un 20 por ciento la mortalidad por cáncer de pulmón en los fumadores pesados o ex fumadores? ¿Cuántos se salvaron por el estudio? ¿A cuántos hubo que estudiar para salvar a los que se salvaron? ¿Cuánto hay que pagar para salvar a los salvados? ¿Y qué pasa con otros que no tenían nada pero que el estudio dijo que tenían y fueron estudiados y alarmados innecesariamente? ¿Y si el dinero utilizado en ese estudio tan sofisticado se utilizara para otras medidas de más bajo costo pero de alto, aunque no tan reluciente impacto?

El estudio de marras (NLST)', permitiéndome redondear las cifras, le hizo a la mitad de la población (27.000 individuos) una radiografía de tórax anual durante tres años, es decir que se hicieron 81.000 radiografías. A la otra mitad, una TCBD anual durante tres años, es decir que se hicieron 81.000 TCBD.

En el grupo de los que se hicieron TCBD hubo 356 muertes por cáncer de pulmón (alrededor de 1,33\% de los individuos en el grupo TCBD). En el grupo de los que se hicieron radiografías hubo 443 muertes por cáncer de pulmón (alrededor de 1,6\% de los individuos en el grupo radiografía).

Groseramente, el $20 \%$ de reducción de la mortalidad por cáncer de pulmón surge de sustraer 356 (muertes por cáncer de pulmón en el grupo TCBD) de 443 (muertos por cáncer de pulmón en el grupo $\mathrm{Rx}$ ) $=87$. Una reducción de 87 muertes de las 443 que se mueren si solo se les realiza radiografía de tórax significa un $20 \%$. Ochenta y siete muertes en 27.000 individuos a los que hubo que hacerles 81.000 TCBD.

Una objeción metodológica para nada soslayable es que el estudio comparó un método, la TCBD, con otro método que tampoco está validado como procedimiento de rutina, la RX, pero no incluyó a un grupo al que no se le hizo ningún procedimiento de rastreo.

Además, en este estudio, la gran mayoría de los hallazgos, es decir las personas a las que se les detectó "algo" fueron falsos positivos. En efecto $96,4 \%$ de los hallazgos en el grupo TCBD y $94,5 \%$ en el grupo radiografía fueron falsos positivos.

Que se les detectó un "falso positivo" quiere decir que se pensó que podían tener un cáncer de pulmón, se los estudió y se concluyó en que no era tal. Dicho en términos de la calle, viene a ser el "me encontraron una mancha en la radiografía, me la estudiaron y gracias a Dios no era nada".

Hay que aclarar que ese "me la estudiaron" para decir que era un "falso positivo" significó estudios que a veces llegaron a ser broncoscopias, anestesias, biopsias, tiempo, dinero y la espada de Damocles (angustia) de estar "con cáncer". Es decir, enfermamos a muchísimos para salvar a unos pocos (tres por cada mil estudiados o 0,3 por cada cien estudiados 01 por cada 300 estudiados).

Imagínense por un momento a 300 individuos de entre 55 y 75 años (la edad de la población estudiada) a los que les vamos a hacer una tomografía por año (900 tomografías) durante tres años para detectar muchas falsas alarmas (los falsos positivos) algunos cánceres, de los cuales la mayoría morirá igual y solo uno, se salvará.

¿Vale la pena?

Si usted supiera con seguridad que ese "uno" que se salva entre los trescientos es usted, o su papá, o su mamá (ni qué hablar de su hijo) seguramente dirá "sí", vale la pena.

$\mathrm{Si}$ usted es el médico-experto dueño del tomógrafo, o el Presidente de la Asociación Argentina de Dueños de Tomógrafos, ni qué hablar.

Si usted es el médico-periodista que genera "una nota sensación" con el nuevo método que "salva vidas", probablemente también este a favor.

Ahora, ¿Si usted es administrador del dinero de la salud de un país honesto en que además de fumadores con cáncer de pulmón, hay niños en la calle, mujeres golpeadas, analfabetos y gente sin trabajo? Y le dicen que con todas esas tomografías le da de comer por mucho tiempo a una buena cantidad de niños y aparte (no se olvide de esto tampoco) le evita a muchos estudiados andar unos meses con la espada de Damocles del falso positivo y que les evita estudios y hasta biopsias. ¿Qué hace amigo?

Yo no dudaría. Aun estando seguro de ser ese potencial beneficiado, no dudaría. Se lo juro.

Cuando hablo de cuidados médicos y de acceso a los servicios de salud, no me gusta hablar de "lo mal que está nuestro país" porque soy consciente de que hay muchos, muchos países que están mucho, mucho peor. Tampoco estoy opinando políticamente; lo hago estructuralmente, no coyunturalmente.

Resulta llamativo lo frecuente con que en estos días uno escucha o lee propaganda larvada en nombre de la salud, respaldando algún método tecnológico salvador y carísimo. La tecnología se está devorando el presupuesto de la salud, los

* Servicio de Medicina Familiar y Comunitaria del Hospital Italiano de Buenos Aires carlos.garcia@ hospitalitaliano.org.ar 
dueños de la tecnología (de los "fierros caros") son unos pocos y la difunden agresivamente. Cada vez más, esos pocos ganan más en detrimento de los muchos (ciudadanos, enfermos y enfermeros, médicos, parteras, cuidadores, etcétera) que tienen cada vez menos recursos.

La tecnología es buena, siempre y cuando sea bien utilizada, siempre y cuando sea racionalmente utilizada. Para eso, tiene que estar el Estado. En salud, la economía de mercado genera mucha inequidad y la inequidad va de la mano con el empeoramiento de todos los indicadores de salud ${ }^{7}$. La inequidad, es terreno fértil para lo que Julian Tudor Hart, defensor a ultranza del socialismo en los cuidados de salud llamara "Ley de cuidados inversos" significando que el acceso a la atención médica o social de calidad varía en proporción inversa a su necesidad en la población asistida ${ }^{8}$.

Hay profusa bibliografía sobre el daño que causa el exceso de estudios especialmente en quienes no tienen síntomas ${ }^{9,10}$, sin embargo la difusión irresponsable y con fines exclusivamente comerciales de panaceas que nos llevan camino a la eternidad, ganan todos los días batallas y lamentablemente podrían ganar la guerra.

Esta medicina de shopping center en la que quienes tienen acceso a los cuidados y aman excesivamente su vida se internan en una clínica (no pocas veces bien reputada) y "se hacen de todo" es lo que Brian Rank llamó en 2008 "Exámenes de ejecutivos - Mala medicina en tres aspectos" por cara, por ineficiente y por inequitativa ${ }^{11}$, medicina que yo, menos retóricamente y más prosaicamente no dudaría en llamar medicina berreta y engañosa, contradiciendo en cierta forma a Tudor Hart porque no todo lo que reluce es oro y esta medicina shopping hace daño aparentando hacer bien a quienes acceden a ella, pero lo peor, mucho peor (y ahí sí se cumple lo de Tudor Hart), le quita recursos a quienes no tienen acceso a ella ni a muchas otras cosas mucho más elementales y más necesarias que una tomografía computada.

Recibido el 07/06/2015 y aceptado el 17/06/2015

García C. El alto costo y las verdades ocultas del exceso de tecnología dedicada al rastreo de personas asintomáticas. Evid Act Pract Amb. 2015;18(2):37-38. Abr-Jun.

\section{Referencias}

1. The National Lung Screening Trial Research Team. Reduced lung-cancer mortality with low-dose computed tomographic screening. N Engl J Med. 2011;365(5):395-409.

2. Elustondo G. La detección temprana de cáncer de pulmón es posible (en línea). Clarín digital; Salud. Disponible en URL: http://entremujeres.clarin.com/vida-sana/salud/deteccion-temprana-cancer-pulmon-posible-tomografia_0_1334276398.html (último acceso junio 2015).

3. Mazzucco J. Cáncer de pulmón: la importancia del buen diagnóstico por imágenes (en linea). Clarín digital; Salud. Disponible en URL: http://entremujeres.clarin.com/vida-sana/salud/cancer_de pulmon-cigarrillo-fumar-tabaco-detectar-diagnostico_por_imagenes_0_1334273253.html (último acceso junio 2015).

4. El cribado del cáncer de pulmón permitiría reducir un $20 \%$ de la muertes (en linea). elPeriodico. 4/feb/2015;Sociedad. Disponible en: http://www.elperiodico.com/es/noticias/sociedad/cribado-del-cancer-pulmon-permitiria-reducir-muertes-3909433 (último acceso junio 2015).

5. De Benito E. La detección precoz del cáncer de pulmón reduce las muertes un 20\% (en línea). El Pais. 17/nov/2014;Ciencia. Disponible en: http://elpais.com/elpais/2014/11/14/ciencia/1415991015 144878.html (último acceso junio 2015).

6. Detección temprana del cáncer de pulmón (en línea). Radiologylnfo.org. Disponible en: http://www.radiologyinfo.org/sp/info.cfm?pg=screening-lung (último acceso junio 2015).

7. Macinko JA,Starfield B. Annotated Bibliography on Equity in Health, 1980-2001. International Journal for Equity in Health 2002;1:1 doi:10.1186/1475-9276-1-1. Disponible en: http://www.equityhealthj.com/content/1/1/1 (último acceso junio 2015).

8. Hart JT. The inverse care law. Lancet. 1971;1(7696):405-12.

9. Welch HG. Overdiagnosed: Making People Sick in the Pursuit of Health. 1ra ed. Beacon Press:2011. Disponible en: http://www.amazon.es/Overdiagnosed-Making-People-PursuitHealth/dp/0807021997 (último acceso junio 2015).

10. Welch HG. Less Medicine more health. 1ra ed. Beacon Press:2015.

11. Rank B. Executive physicals--bad medicine on three counts. N Engl J Med. 2008;359(14):1424-5.

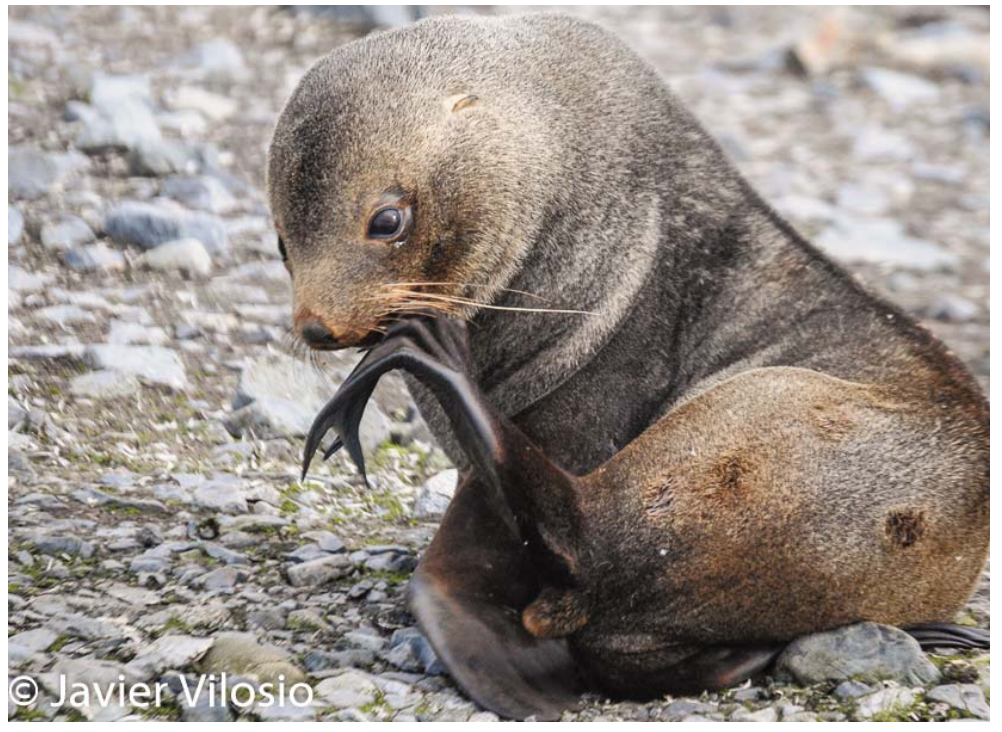

Lobo marino, antártico (Arctophoca gazella). Sector antártico argentino. Cortesia de: Javier Vilosio.

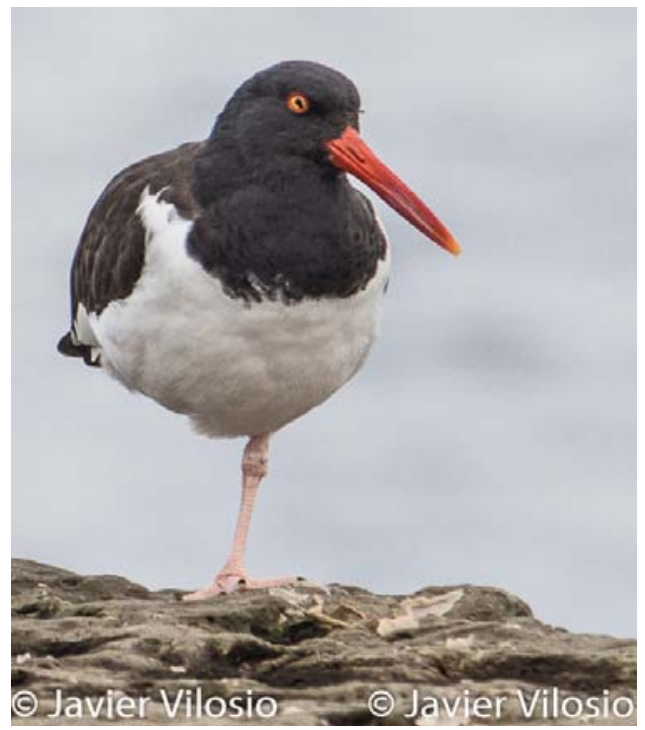

Ostrero Austral (Haematopus leucopodus). Pta. Pardelas, Peninsula de Valdes, Chubut. Cortesia de: Javier Vilosio 